\title{
Association between legalization of recreational cannabis and fatal motor vehicle collisions in the United States: an ecologic study
}

\author{
Sarah B. Windle MPH, Mark J. Eisenberg MD MPH, Pauline Reynier MSc, Josselin Cabaussel MSc, \\ Brett D. Thombs PhD, Roland Grad MD MSc, Carolyn Ells PhD, Crystal Sequeira MScA, \\ Kristian B. Filion PhD
}

\section{Abstract}

Background: With the recent legalization of recreational cannabis in Canada, cannabis-impaired driving is an important public safety concern. Our aim was to examine the association between recreational cannabis legalization and fatal motor vehicle collisions using data from the United States, which present a timely natural experiment of cannabis legalization.

Methods: We conducted an ecologic study using the number of fatal motor vehicle collisions and the associated number of deaths for US jurisdictions with legalized recreational cannabis (2007-2018) retrieved from the US Fatality Analysis Reporting System. We examined jurisdiction-specific rates of fatal motor vehicle collisions and associated deaths before and after recreational cannabis legalization using Poisson regression and meta-analyzed estimates across jurisdictions using DerSimonian and Laird random-effects models.

Results: After adjustment for calendar year, legalization was associated with increases in rates of fatal motor vehicle collisions (incidence rate ratio $[\mathrm{IRR}] 1.15,95 \%$ confidence interval $[\mathrm{Cl}] 1.06-1.26)$ and associated deaths (IRR 1.16, 95\% Cl 1.06-1.27). Differences between the first 12 months after legalization relative to subsequent months were inconclusive for rates of fatal motor vehicle collisions (IRR 0.92, 95\% Cl 0.84-1.02) and associated deaths (IRR 0.92, 95\% Cl 0.84-1.01).

Interpretation: Recreational cannabis legalization in the US was associated with a relative increased risk of fatal motor vehicle collisions of $15 \%$ and a relative increase in associated deaths of $16 \%$, with no conclusive difference between the first and subsequent years after legalization. These findings raise concern that there could be a similar increase in fatal motor vehicle collisions and associated deaths in Canada following recreational cannabis legalization.

anada legalized recreational cannabis nationally on Oct. 17, 2018. By 2019, more than 5.1 million Canadians $(16.8 \%$ of the population aged $\geq 15 \mathrm{yr}$ ) reported cannabis use in the previous 3 months (compared to $14.9 \%$ before legalization). ${ }^{1}$ Although legalization better aligned the law with Canadian values and practices, it raised public health concerns regarding impaired driving. ${ }^{2}$ Of people who reported any cannabis use in the previous 3 months, $13.2 \%$ reported driving within 2 hours of consuming cannabis; this proportion increased to $28.8 \%$ among daily or almost daily cannabis users. ${ }^{1}$ The relation between cannabis use and impaired driving is complicated by varied methods of consumption (e.g., smoking, vaping, edibles), individual factors (e.g., metabolism, frequency of use) and time since consumption, as well as challenges in the reliable assessment of cannabis impairment. ${ }^{3}$ However, cannabis is known to affect psychomotor skills necessary for driving, including critical tracking, divided attention and reaction time. ${ }^{4}$

Despite this knowledge, few studies have examined the impact of large-scale public policies that increased access to cannabis on impaired driving and related outcomes. Given the varied approaches taken to cannabis regulation by different jurisdictions in the United States, ${ }^{5}$ data from the US present a timely natural experiment to assess the impact of recreational cannabis legalization. Our objective was to examine the association between recreational cannabis legalization and the rate of fatal motor vehicle collisions in the US to inform impaired-driving policy and public health prevention measures in Canada.

\section{Methods}

\section{Design and setting}

We performed an ecologic study to examine the association between recreational cannabis legalization and fatal

Competing interests: None declared.

This article has been peer reviewed.

Correspondence to: Kristian Filion, kristian.filion @ mcgill.ca

CMAJ Open 2021. DOI:10.9778/cmajo.20200155 
motor vehicle collisions and associated deaths in the US between 2007 and 2018. Legalization was in effect in 11 jurisdictions (10 states and the District of Columbia) before 2019 (Table 1). ${ }^{29}$

\section{Data sources}

We retrieved the number of fatal motor vehicle collisions and of deaths due to motor vehicle collisions (as each collision could result in more than 1 fatality) by month for US jurisdictions with legalized recreational cannabis from the US Fatality Analysis Reporting System (FARS). ${ }^{30}$ The FARS database includes data on collisions that occur on public roadways and result in at least 1 death within 30 days. We selected 2007 as the start of our study period to include at least 5 years before the first year in which legalized recreational cannabis was in effect in any jurisdiction (2012). Although recreational cannabis legalization came into effect in other states after 2019, we did not include those jurisdictions because the most recent year of FARS data available at the time of analysis (September 2020) was 2018.

The FARS database is the only source of national-level statistics on police-reported fatalities in the US, with data collected through collaborative agreements between the National Highway Traffic Safety Administration and each state. ${ }^{31}$ Data collection forms for FARS are completed by personnel trained by the National Highway Traffic Safety Administration using multiple source documents (e.g., police, medical and administrative reports) and entered into a standardized, validated database..$^{31,32}$

\section{Exposure definitions}

We defined exposure using a time-dependent approach with 2 categories: legalized recreational cannabis and no legalized recreational cannabis (reference group). We defined legalization for each jurisdiction as the date on which recreational cannabis legalization was in effect, rounded up or down to the nearest full month. Each jurisdiction contributed person-time of observation (determined with the use of the annual population of each jurisdiction for each year between 2007 and 2018) $)^{30}$ and data on fatal motor vehicle collisions to both categories (legalized and nonlegalized) in the analysis.

\section{Statistical analysis}

We estimated the rates of fatal motor vehicle collisions and associated deaths within each jurisdiction before and after recreational cannabis legalization. Rates were estimated per 100000 person-years for years during which recreational

Table 1: United States jurisdictions with regulations for legalized recreational cannabis in effect before 2019

\begin{tabular}{|c|c|c|c|c|c|}
\hline Jurisdiction & $\begin{array}{l}\text { Date legalization } \\
\text { in effect }\end{array}$ & $\begin{array}{l}\text { First month } \\
\text { legalization in } \\
\text { effect for primary } \\
\text { analysis* }\end{array}$ & $\begin{array}{l}\text { Date commercial } \\
\text { dispensaries } \\
\text { open }\end{array}$ & $\begin{array}{c}\text { First month } \\
\text { commercial } \\
\text { dispensaries open } \\
\text { for sensitivity } \\
\text { analysis* }^{*}\end{array}$ & $\begin{array}{c}\text { Cannabis-specific impaired } \\
\text { driving law }{ }^{6}\end{array}$ \\
\hline Alaska ${ }^{7,8}$ & Feb. 24, 2015 & March 2015 & Oct. 29, 2016 & November 2016 & None \\
\hline California ${ }^{9,10}$ & Nov. 9, 2016 & November 2016 & Jan. 1, 2018 & January 2018 & None \\
\hline Colorado ${ }^{11,12}$ & Dec. 10, 2012 & December 2012 & Jan. 1, 2014 & January 2014 & $\begin{array}{l}\text { Reasonable inference for } \\
\text { impairment } \geq 5 \mathrm{ng} / \mathrm{mL} \mathrm{THC} \dagger\end{array}$ \\
\hline $\begin{array}{l}\text { District of } \\
\text { Columbia }^{13}\end{array}$ & Feb. 26, 2015 & March 2015 & $\begin{array}{l}\text { No commercial } \\
\text { dispensaries }\end{array}$ & NA & None \\
\hline Maine $e^{14,15}$ & Jan. 30, 2017 & February 2017 & Oct. 9, 2020 & NA & None \\
\hline Massachusetts $^{16,17}$ & Dec. 15, 2016 & December 2016 & Nov. 20, 2018 & December 2018 & None \\
\hline Michigan ${ }^{18-20}$ & Dec. 6, 2018 & December 2018 & Dec. 1, 2019 & NA & $\begin{array}{l}\text { Zero tolerance (no detectable } \\
\text { presence of cannabis } \\
\text { permitted) }\end{array}$ \\
\hline Nevada $^{21,22}$ & Jan. 1, 2017 & January 2017 & July 1, 2017 & July 2017 & Per se limit $\geq 2$ ng/mL THC§ \\
\hline Oregon ${ }^{23-25}$ & July 1, 2015 & July 2015 & Oct. 1, 2015 & October 2015 & None \\
\hline Vermont ${ }^{26}$ & July 1, 2018 & July 2018 & $\begin{array}{l}\text { No commercial } \\
\text { dispensaries }\end{array}$ & NA & None \\
\hline Washington ${ }^{27,28}$ & Dec. 6, 2012 & December 2012 & July 8, 2014 & July 2014 & Per se limit $\geq 5 \mathrm{ng} / \mathrm{mL}$ THC§ \\
\hline \multicolumn{6}{|c|}{$\begin{array}{l}\text { Note: NA = no data available for legalized (or commercial dispensaries open) months before } 2019, \text { THC }=\text { tetrahydrocannabinol. } \\
\text { "Rounded up or down to the nearest full month of legalization (or commercial dispensaries opening, for sensitivity analysis). } \\
\text { tReasonable inference requires that the jurisdiction must prove with other evidence, in addition to exceeding the legal THC limit, that the driver was impaired. } \\
\text { fOn Dec. } 1,2019 \text {, existing medical cannabis dispensaries in Michigan were permitted to transfer up to } 50 \% \text { of their medical cannabis inventory to recreational cannabis } \\
\text { inventory. Until November } 2021 \text {, retailers must hold a medical cannabis licence in order to apply for a recreational cannabis licence. } \\
\text { \$Per se limits do not require that the jurisdiction prove that drivers were impaired in order to charge them with driving under the influence if their THC level exceeded the } \\
\text { legal limit. } \\
\text { ๆOn Oct. } 1,2015 \text {, existing medical cannabis dispensaries in Oregon were permitted to sell recreational cannabis. The first licences were issued to recreational cannabis } \\
\text { retailers on Oct. } 1,2016 \text {. }\end{array}$} \\
\hline
\end{tabular}


cannabis was legal and not legal for each included jurisdiction. We then determined crude and adjusted incidence rate ratios (IRRs) and 95\% confidence intervals (CIs) for each jurisdiction using a generalized linear model with a log link and Poisson distribution by means of the proc genmod procedure in SAS (version 9.4) (SAS Institute) for the associations between recreational cannabis legalization and fatal motor vehicle collisions and fatalities due to motor vehicle collisions. We adjusted models for calendar year, which was modelled as a continuous variable, to account for underlying time trends (e.g., baseline trends in substance use and driving, impaired-driving policies). We then meta-analyzed jurisdiction-specific estimates using DerSimonian and Laird random-effects models with inverse variance weighting. We conducted the meta-analysis in R (R Foundation for Statistical Computing) using the meta package.

We performed 2 secondary analyses. In the first, we defined exposure using the date when commercial cannabis dispensaries opened (rounded up or down to the nearest full month) instead of the date that legalization came into effect. Commercial dispensaries were open in 7 states before 2019 (Alaska, California, Colorado, Massachusetts, Nevada, Oregon and Washington). The remaining jurisdictions did not plan to allow dispensaries or opened (or planned to open) dispensaries after the study period.
In the other secondary analysis, we subcategorized data from the months during which cannabis was legal (or the months during which commercial dispensaries were opened) into the first 12 months and subsequent months to assess whether any observed increased risk was short term. We then compared rates from the first 12 months and subsequent months to each other and to those from nonlegalized periods.

In sensitivity analyses, we used a fixed-effects rather than a random-effects model. We also examined temporal trends in the incidence of fatal motor vehicle collisions and associated deaths before legalization to visually assess whether these were log-linear. We assessed colinearity between calendar year and legalization and open dispensaries using the variance inflation factor.

\section{Ethics approval}

Ethics approval was not required for this research as it used publicly available data.

\section{Results}

A total of 73982 fatal motor vehicle collisions resulting in 80402 deaths occurred between 2007 and 2018 in the 11 US jurisdictions that had recreational cannabis legalization in effect before 2019 (Table 2). Of these collisions,

Table 2: Fatal motor vehicle collisions and associated deaths from 2007 to 2018 in United States jurisdictions with legalized recreational cannabis

\begin{tabular}{|c|c|c|c|c|c|}
\hline \multirow[b]{2}{*}{ Event } & \multirow{2}{*}{$\begin{array}{l}\text { No. of } \\
\text { events }\end{array}$} & \multirow{2}{*}{$\begin{array}{l}\text { Person-years of } \\
\text { observation }\end{array}$} & \multirow{2}{*}{$\begin{array}{c}\text { Rate per } \\
100000 \text { person- } \\
\text { years }(95 \% \mathrm{Cl})\end{array}$} & \multicolumn{2}{|c|}{ IRR $(95 \% \mathrm{CI})$} \\
\hline & & & & Crude & Adjusted* \\
\hline \multicolumn{6}{|l|}{$\begin{array}{l}\text { Recreational cannabis legalization } \\
\text { (11 jurisdictions)†‡ }\end{array}$} \\
\hline Fatal motor vehicle collision & 73982 & 924545813 & $8.00(7.94-8.06)$ & & \\
\hline No legalization & 56866 & 717561813.4 & $7.92(7.86-7.99)$ & 1.00 (reference) & 1.00 (reference) \\
\hline Legalization & 17116 & 206983999.6 & $8.27(8.15-8.39)$ & $1.05(0.99-1.12)$ & $1.15(1.06-1.26)$ \\
\hline Death from motor vehicle collision & 80402 & 924545813 & $8.70(8.64-8.76)$ & & \\
\hline No legalization & 61822 & 717561813.4 & $8.62(8.55-8.68)$ & 1.00 (reference) & 1.00 (reference) \\
\hline Legalization & 18580 & 206983999.6 & $8.98(8.85-9.11)$ & $1.04(0.98-1.11)$ & $1.16(1.06-1.27)$ \\
\hline \multicolumn{6}{|l|}{$\begin{array}{l}\text { Opening of recreational cannabis } \\
\text { dispensaries ( } 7 \text { jurisdictions)†§ }\end{array}$} \\
\hline Fatal motor vehicle collision & 60518 & 774128598 & $7.82(7.76-7.88)$ & & \\
\hline No open dispensaries & 50275 & 653841729.2 & $7.69(7.62-7.76)$ & 1.00 (reference) & 1.00 (reference) \\
\hline Open dispensaries & 10243 & 120286868.8 & $8.52(8.35-8.68)$ & $1.08(1.03-1.14)$ & $1.18(1.06-1.32)$ \\
\hline Death from motor vehicle collision & 65835 & 774128598 & $8.50(8.44-8.57)$ & & \\
\hline No open dispensaries & 54685 & 653841729.2 & $8.36(8.29-8.43)$ & 1.00 (reference) & 1.00 (reference) \\
\hline Open dispensaries & 11150 & 120286868.8 & $9.27(9.10-9.44)$ & $1.08(1.03-1.14)$ & $1.18(1.06-1.32)$ \\
\hline \multicolumn{6}{|c|}{$\begin{array}{l}\text { Note: } \mathrm{Cl}=\text { confidence interval, IRR = incidence rate ratio. } \\
\text { *Adjusted for calendar year, modelled as a continuous variable. } \\
\text { †See Appendix } 1 \text {, Supplemental Tables } \mathrm{S} 1-\mathrm{S} 4 \text { (available at www.cmajopen.ca/content/9/1/E233/suppl/DC1) for jurisdiction-specific event rates. } \\
\text { †The variance inflation factor for calendar year and legalization status ranged from } 1.02 \text { in Michigan to } 4.03 \text { in Colorado and Washington (Appendix } 1 \text {, Supplemental } \\
\text { Table S5). } \\
\text { §The variance inflation factor for calendar year and open dispensary status ranged from } 1.02 \text { in Michigan to } 3.76 \text { in Colorado (Appendix 1, Supplemental Table S5). }\end{array}$} \\
\hline
\end{tabular}


17116 , resulting in 18580 deaths, occurred during periods when recreational cannabis was legal (Table 2; Appendix 1, Supplemental Tables S1-S4, available at www.cmajopen.ca/ content/9/1/E233/suppl/DC1).

After adjustment for calendar year, legalization was associated with increased rates of fatal motor vehicle collisions (IRR $1.15,95 \%$ CI 1.06-1.26) (Figure 1A) and deaths from motor vehicle collisions (IRR 1.16, 95\% CI 1.06-1.27) (Figure 1B). When we used the date commercial dispensaries opened rather than the date legalization came into effect in the analyses, the findings were similar for the risk of motor vehicle collisions (IRR 1.18, 95\% CI 1.06-1.32) (Figure 2A) and associated deaths (IRR 1.18, 95\% CI 1.06-1.32) (Figure 2B).

After adjustment for calendar year, the difference in the first 12 months versus subsequent months after legalization was inconclusive for rates of fatal motor vehicle collisions (IRR 0.92, 95\% CI 0.84-1.02) and deaths from motor vehicle collisions (IRR 0.92, 95\% CI 0.84-1.01) (Table 3). When we used the date dispensaries opened rather than the date legalization came into effect in the analyses, we likewise found an inconclusive difference in rates of fatal motor vehicle collisions (IRR 0.88, 95\% CI 0.76-1.02) and associated deaths (IRR $0.88,95 \%$ CI $0.76-1.01$ ) in the first 12 months versus subsequent months (Table 3 ).

\section{Sensitivity analysis}

Sensitivity analyses that used fixed-effects models showed results similar to those of the random-effects models for both rates of fatal motor vehicle collisions and deaths associated with recreational cannabis legalization (Figure 1) and the
A

Jurisdiction

Alaska

California

Colorado

District of Columbia

Maine

Massachusetts

Michigan

Nevada

Oregon

Vermont

Washington
Legalization

Events Person-years

$278 \quad 2834487.0$

$7475 \quad 85635367.5$

$3168 \quad 33356368.5$

$106 \quad 2637787.0$

$277 \quad 2562985.4$

$703 \quad 14329616.2$

832992.9

6032431.0

14441442.5

313149.5

44007372.0

Fixed-effects model

Random-effects model

Heterogeneity: $I^{2}=82 \%(68 \%-89 \%), \tau^{2}=0.0147$
B

Jurisdiction
Alaska
California
Colorado
District of Columbia
Maine
Massachusetts
Michigan
Nevada
Oregon
Vermont
Washington

Fixed-effects model

Random-effects model

Heterogeneity: $I^{2}=85 \%(75 \%-91 \%), \tau^{2}=0.0176$
No legalization

Events Person-years

$479 \quad 5827578.0$

$29150 \quad 372247029.5$

$2638 \quad 29726994.5$

$199 \quad 5049204.0$

$1447 \quad 13368228.6$

$3436 \quad 65799402.8$

$10661 \quad 118469766.1$

$2678 \quad 27451576.0$

$2825 \quad 32880250.5$

$676 \quad 7183101.5$

$2677 \quad 39558682.0$

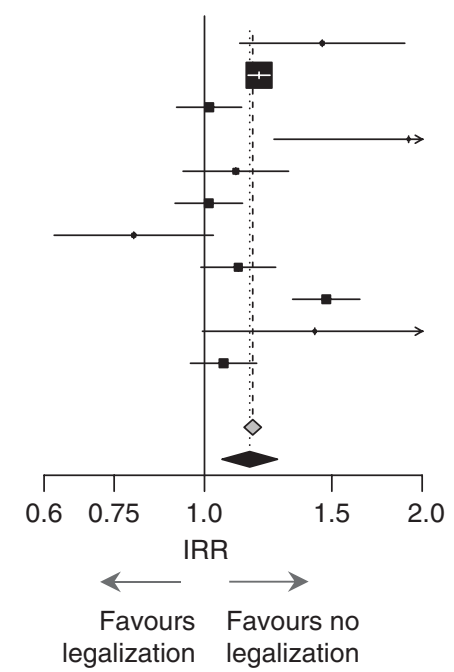

Adjusted IRR

(95\% Cl)*

1.45 (1.12-1.89)

1.19 (1.15-1.23)

$1.01(0.92-1.13)$

$1.92(1.25-2.94)$

$1.10(0.93-1.31)$

$1.01(0.91-1.13)$

$0.80(0.62-1.03)$

$1.11(0.99-1.25)$

$1.47(1.32-1.64)$

$1.42(0.99-2.03)$

$1.06(0.96-1.18)$

$1.17(1.13-1.20)$

1.15 (1.06-1.26)
No legalization Events Person-years Events Person-years

$\begin{array}{rrr}304 & 2834487.0 \\ 8136 & 85635367.5 \\ 3439 & 33356368.5 \\ 110 & 2637787.0 \\ 294 & 2562985.4 \\ 740 & 14329616.2 \\ 63 & 832992.9 \\ 641 & 6032431.0 \\ 1680 & 14441442.5 \\ 42 & 313149.5 \\ 3131 & 44007372.0\end{array}$

$523 \quad 5827578.0$

$31765 \quad 372247029.5$

$2904 \quad 29726994.5$

$218 \quad 5049204.0$

$1565 \quad 13368228.6$

364565799402.8

11532118469766.1

$2916 \quad 27451576.0$

$3112 \quad 32880250.5$

$743 \quad 7183101.5$

289939558682.0

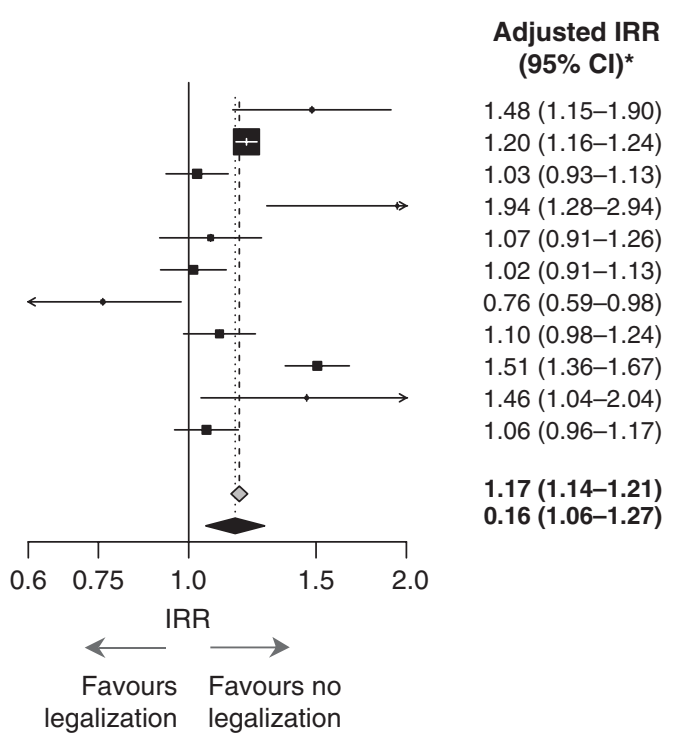

Figure 1: Forest plot of fatal motor vehicle collisions (A) and associated deaths (B) from 2007 to 2018 in United States jurisdictions with legalized recreational cannabis. *Adjusted for calendar year, modelled as a continuous variable. Note: $\mathrm{Cl}=$ confidence interval, IRR $=$ incidence rate ratio. 
A

\begin{tabular}{lrr} 
Jurisdiction & \multicolumn{2}{c}{ Open dispensaries } \\
Events & Person-years \\
Alaska & 159 & 1600882.0 \\
California & 3259 & 39557045.0 \\
Colorado & 2704 & 27655703.0 \\
Massachusetts & 30 & 575179.1 \\
Nevada & 446 & 4533411.5 \\
Oregon & 1402 & 13434198.2 \\
Washington & 2243 & 32930450.0 \\
& & \\
Fixed-effects model & & \\
Random-effects model & & \\
Heterogeneity: $l^{2}=86 \%(72 \%-92 \%), \tau^{2}=0.0161$
\end{tabular}

B

$\begin{array}{lrr}\text { Jurisdiction } & \begin{array}{l}\text { Opents } \\ \text { Everson-years }\end{array} \\ \text { Alaska } & 174 & 1600882.0 \\ \text { California } & 3563 & 39557045.0 \\ \text { Colorado } & 2923 & 27655703.0 \\ \text { Massachusetts } & 32 & 575179.1 \\ \text { Nevada } & 487 & 4533411.5 \\ \text { Oregon } & 1553 & 13434198.2 \\ \text { Washington } & 2418 & 32930450.0 \\ & & \\ \text { Fixed-effects model } & & \\ \text { Random-effects model } & \\ \text { Heterogeneity: } I^{2}=86 \%(72 \%-92 \%), \tau^{2}=0.0161\end{array}$

No open dispensaries

Events Person-years

$\begin{array}{rr}598 & 7061183.0 \\ 33366 & 418325352.0 \\ 3102 & 35427660.0 \\ 4109 & 79553839.9 \\ 2824 & 28950595.5 \\ 2943 & 33887494.8 \\ 3333 & 50635604.0\end{array}$

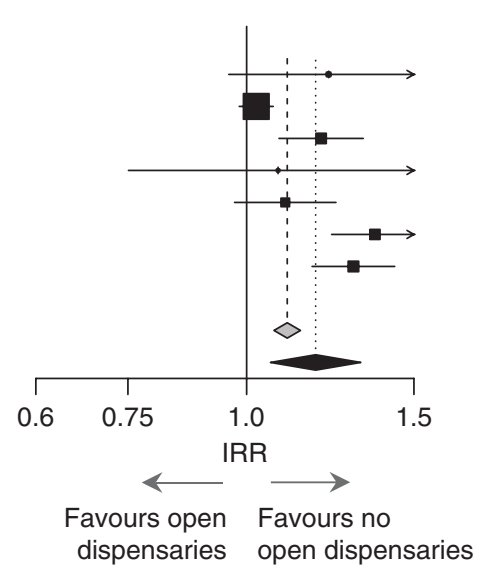

No open dispensaries Events Person-years

$\begin{array}{rr}653 & 7061183.0 \\ 36338 & 418325352.0 \\ 3420 & 35427660.0 \\ 4353 & 79553839.9 \\ 3070 & 28950595.5 \\ 3239 & 33887494.8 \\ 3612 & 50635604.0\end{array}$

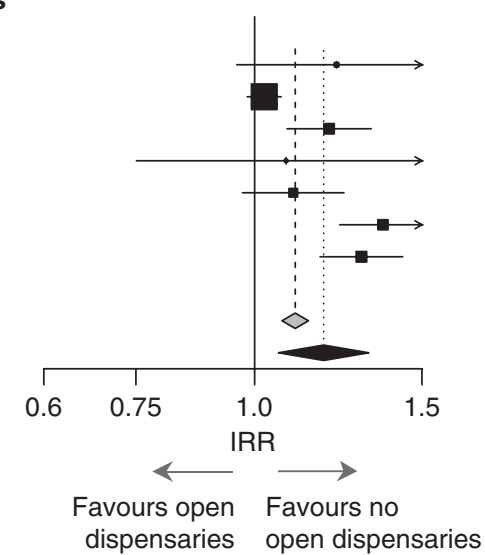

Adjusted IRR $(95 \% \mathrm{Cl})^{\star}$

$1.22(0.96-1.55)$

$1.02(0.98-1.07)$

$1.20(1.08-1.33)$

$1.08(0.75-1.55)$

$1.10(0.97-1.24)$

$1.36(1.23-1.52)$

$1.30(1.17-1.43)$

$1.10(1.07-1.14)$

$1.18(1.06-1.32)$

Adjusted IRR

$(95 \% \mathrm{Cl})^{\star}$

$1.22(0.96-1.55)$

$1.02(0.98-1.07)$

$1.20(1.08-1.33)$

$1.08(0.75-1.55)$

$1.10(0.97-1.24)$

$1.36(1.23-1.52)$

$1.30(1.17-1.43)$

$1.10(1.07-1.14)$

$1.18(1.06-1.32)$

Figure 2: Forest plot of fatal motor vehicle collisions (A) and associated deaths (B) from 2007 to 2018 in United States jurisdictions with open recreational cannabis dispensaries. *Adjusted for calendar year, modelled as a continuous variable. $\mathrm{Note}$ : $\mathrm{Cl}=\mathrm{confidence}$ interval, IRR $=$ incidence rate ratio.

opening of dispensaries (Figure 2). Temporal trends in the incidence of fatal motor vehicle collisions and associated deaths before legalization were roughly log-linear, although mild departures were present in some jurisdictions. The variance inflation factor between calendar year and legalization for fatal collisions ranged from 1.02 in Michigan to 4.03 in Colorado and Washington (Appendix 1, Supplemental Table S5). The IRR for calendar year and fatal motor vehicle collisions ranged from 0.90 (95\% CI $0.85-0.96)$ in the District of Columbia to 1.003 (95\% CI 0.99-1.01) in Michigan, with a similar range for associated deaths. Similar findings were obtained for the variance inflation factor for opening of dispensaries.

\section{Interpretation}

We found that recreational cannabis legalization in US jurisdictions was associated with a relative increased risk of fatal motor vehicle collisions of $15 \%$ and a relative increase in associated deaths of $16 \%$. From the FARS database, in 2018, an estimated 30270 motor vehicle fatalities occurred in jurisdictions without legalized recreational cannabis. Our results suggest that legalization on a national scale could result in an additional 4843 motor vehicle fatalities per year in the US.

Previous literature concerning the association between cannabis legalization and impaired driving is limited. A small number of observational studies suggest that medical or recreational cannabis legalization may increase the proportion of drivers with detectable levels of cannabis in analyses of blood or urine; however, these observations may be confounded by increases in enforcement activities and in cannabis testing and reporting following legalization. ${ }^{3-36}$ Likewise, an increase in detectable levels of cannabis (e.g., owing to increased use following legalization) would not necessarily correspond directly to increases in impaired driving. ${ }^{3}$ Another study showed an increase in self-reported driving under the influence of cannabis following legalization. ${ }^{37}$ However, people may be more likely to report cannabis use and temporally associated driving when cannabis use is legal. 


\begin{tabular}{|c|c|c|c|c|c|}
\hline \multirow[b]{2}{*}{ Event } & \multirow{2}{*}{$\begin{array}{l}\text { No. of } \\
\text { events }\end{array}$} & \multirow{2}{*}{$\begin{array}{l}\text { Person-years } \\
\text { of observation }\end{array}$} & \multirow{2}{*}{$\begin{array}{l}\text { Rate per } \\
100000 \text { person- } \\
\text { years }(95 \% \mathrm{Cl})\end{array}$} & \multicolumn{2}{|c|}{$\operatorname{IRR}(95 \% \mathrm{Cl})$} \\
\hline & & & & Crude & Adjusted* $^{*}$ \\
\hline \multicolumn{6}{|l|}{ Recreational cannabis legalization } \\
\hline Fatal motor vehicle collision & 73982 & 924545813 & $8.00(7.94-8.06)$ & & \\
\hline No legalization & 68180 & 855020030.8 & $7.92(7.86-7.99)$ & 1.00 (reference) & 1.00 (reference) \\
\hline First 12 mo after legalization $\dagger$ & 5802 & 69525782.3 & $8.35(8.13-8.56)$ & $1.01(0.93-1.11)$ & $1.12(1.01-1.23)$ \\
\hline Subsequent months after legalization $\ddagger$ & 11314 & 137458217.3 & $8.23(8.08-8.38)$ & $1.06(1.00-1.13)$ & $1.22(1.11-1.35)$ \\
\hline First 12 mo v. subsequent months & - & - & - & $0.96(0.88-1.05)$ & $0.92(0.84-1.02)$ \\
\hline Death from motor vehicle collision & 80402 & 924545813 & $8.70(8.64-8.76)$ & - & \\
\hline No legalization & 61822 & 717561813.4 & $8.62(8.55-8.68)$ & 1.00 (reference) & 1.00 (reference) \\
\hline First $12 \mathrm{mo}$ after legalization $\dagger$ & 6290 & 69525782.3 & $9.05(8.83-9.27)$ & $1.00(0.92-1.10)$ & $1.11(1.00-1.24)$ \\
\hline Subsequent months after legalization $\ddagger$ & 12290 & 137458217.3 & $8.94(8.78-9.10)$ & $1.06(1.00-1.12)$ & $1.23(1.11-1.37)$ \\
\hline First 12 mo v. subsequent monthsł & - & - & - & $0.96(0.89-1.04)$ & $0.92(0.84-1.01)$ \\
\hline \multicolumn{6}{|l|}{$\begin{array}{l}\text { Opening of recreational cannabis } \\
\text { dispensaries }\end{array}$} \\
\hline Fatal motor vehicle collision & 60518 & 774128598 & $7.82(7.76-7.88)$ & & \\
\hline No open dispensaries & 50275 & 653841729.2 & $7.69(7.62-7.76)$ & 1.00 (reference) & 1.00 (reference) \\
\hline First 12 mo of open dispensaries $\dagger$ & 4968 & 60437733.9 & $8.22(7.99-8.45)$ & $1.03(0.95-1.13)$ & $1.13(1.03-1.24)$ \\
\hline $\begin{array}{l}\text { Subsequent months of open } \\
\text { dispensaries } \ddagger\end{array}$ & 5275 & 59849134.9 & $8.81(8.58-9.05)$ & $1.13(1.08-1.18)$ & $1.34(1.24-1.46)$ \\
\hline First 12 mo v. subsequent monthsł & - & - & - & $0.92(0.82-1.04)$ & $0.88(0.76-1.02)$ \\
\hline Death from motor vehicle collision & 65835 & 774128598 & $8.50(8.44-8.57)$ & & \\
\hline No open dispensaries & 54685 & 653841729.2 & $8.36(8.29-8.43)$ & 1.00 (reference) & 1.00 (reference) \\
\hline First 12 mo of open dispensaries $\dagger$ & 5426 & 60437733.9 & $8.98(8.74-9.22)$ & $1.03(0.95-1.13)$ & $1.13(1.03-1.25)$ \\
\hline $\begin{array}{l}\text { Subsequent months of open } \\
\text { dispensaries§ }\end{array}$ & 5724 & 59849134.9 & $9.56(9.32-9.82)$ & $1.12(1.07-1.17)$ & $1.35(1.25-1.45)$ \\
\hline First 12 mo v. subsequent months§ & - & - & - & $0.92(0.82-1.03)$ & $0.88(0.76-1.01)$ \\
\hline \multicolumn{6}{|c|}{$\begin{array}{l}\text { Note: } \mathrm{Cl}=\text { confidence interval, IRR = incidence rate ratio. } \\
\text { "Adjusted for calendar year, modelled as a continuous variable. } \\
\text { tIncludes up to } 12 \text { months for each jurisdiction (some jurisdictions contributed less than } 12 \mathrm{mo} \text {, depending on their dates of legalization or opening of dispensaries). } \\
\text { †Excludes Michigan and Vermont (no subsequent months of legalization available). } \\
\text { §Excludes California and Massachusetts (no subsequent months of open dispensaries available). }\end{array}$} \\
\hline
\end{tabular}

Several previous studies in which ecologic approaches were used did not rely on the measurement and reporting of the presence of cannabis or data on self-reported impaired driving. Aydelotte and colleagues ${ }^{38}$ used a difference-in-differences approach to compare changes in fatal motor vehicle collisions associated with legalization, using FARS data (2007-2017) from Colorado and Washington and 9 control states. Although their results were not conclusive, their analysis suggested a potential increase in fatal collisions of 1.2 per billion vehicle miles travelled ( $95 \% \mathrm{CI}-0.6$ to 2.1 ) in Colorado and Washington in the 5 years after recreational cannabis legalization. When they used the date of opening of commercial dispensaries, legalization was associated with an increase in fatal collisions of 1.8 per billion vehicle miles travelled (95\% CI $0.4-3.7)$. Santaella-Tenoirio and colleagues ${ }^{39}$ examined similar $^{2}$ data (2005-2017) from Colorado and Washington, which they compared to synthetic reference groups (created from a pool of comparison states whose fatality rates best resembled those of the exposed states before legalization). They found an increase in motor vehicle fatalities in Colorado (1.5/billion vehicle miles travelled, $p=0.047$ ) but not in Washington $(0.08 /$ billion vehicle miles travelled, $p=0.7)$ following legalization of recreational cannabis retail sales. They hypothesized that higher retail density, cannabis use and cannabis tourism in Colorado relative to Washington may have contributed to the observed increase in fatalities from collisions in Colorado.

Two additional ecologic studies included data from other states with recreational cannabis legalization. Kamer and colleagues $^{40}$ used a difference-in-differences approach to compare motor vehicle fatalities in the FARS database (20082018) in Colorado, Washington, Oregon and Alaska to those in the 20 states without legalized recreational or medical 
cannabis as of the beginning of 2018. After adjusting for covariates, they found an increase in motor vehicle fatalities of 2.1 per billion vehicle miles travelled (95\% CI 1.3-3.0) following the opening of recreational cannabis retail stores. Lane and colleagues ${ }^{41}$ used data from the Centers for Disease Control and Prevention's Wide-ranging Online Data for Epidemiologic Research Web application and RoadSafetyBC to examine changes in traffic fatalities between 2009 and 2016 in 3 states with recreational cannabis legalization (Colorado, Washington and Oregon), using neighbouring jurisdictions without legalization as comparators. They conducted an interrupted time-series analysis of traffic fatality rates using generalized least squares regression models adjusted for seasonality and autocorrelation to test the association between legalization and traffic fatalities. They found a pooled step increase of 1.08 traffic fatalities per million residents $(p<$ 0.001 ), which suggested an increase in traffic fatalities less than 1 year after legalization, followed by a reduction in trend of 0.06 per month $(p<0.001)$.

Our analysis extends the findings of these previous studies by including an additional 7 jurisdictions with recreational cannabis legalization through 2018. Overall, our results support previous literature suggesting that recreational cannabis legalization is associated with increased impaired driving. Although our findings suggest that there may be some variability between jurisdictions in increased risk, IRRs for 10 of the 11 jurisdictions were greater than 1.0 (range 1.01-1.92) for fatal motor vehicle collisions following legalization. Michigan was the only jurisdiction with a point estimate that suggested a lower risk after legalization (IRR 0.80); however, recreational cannabis was legal for only 1 month in that state before 2019. Among jurisdictions with recreational cannabis dispensaries, all point estimates suggested increased rates of fatal motor vehicle collisions after the opening of dispensaries (IRR range 1.02-1.36).

In contrast to the findings of Lane and colleagues, ${ }^{41}$ our findings suggest that the increase in fatal motor vehicle collisions may be sustained over time. We found no evidence of a transient increase in rates of fatal collisions and associated deaths in the first 12 months following legalization or the opening of commercial dispensaries compared to subsequent months. However, our estimates suggest that there may be lower rates of fatal collisions and associated deaths in the first 12 months after legalization relative to subsequent months. This may be due to relatively limited cannabis availability in many jurisdictions during the first years after legalization and opening of dispensaries (e.g., fewer stores open, product shortages owing to high demand), which might deter new cannabis users in particular.

In Canada, 1922 motor vehicle fatalities were reported in $2018 ;^{42}$ a relative increase of $16 \%$ would correspond to 308 additional deaths yearly. However, the national approach taken to recreational cannabis legalization may mitigate increases in impaired driving in Canada. For example, Bill C-46 (enacted in 2018) established national per se driving limits for tetrahydrocannabinol (THC), with corresponding minimum penalties for exceeding these limits. ${ }^{43}$ Although these limits are controversial owing to a lack of direct correlation between THC levels and driving impairment, ${ }^{44,45}$ public awareness of the establishment of legal limits alone has the potential to decrease substance-impaired driving. ${ }^{46,47}$ Of the 11 US jurisdictions included in our analyses, 7 did not have a threshold limit for THC. ${ }^{6}$ Overall, our analysis suggests that Canada should remain vigilant regarding the potential for increases in cannabis-impaired driving.

\section{Limitations}

Our study was observational, and there were several factors that varied between jurisdictions and were likely to influence fatal motor vehicle collisions (e.g., substance use, population density, speed limits). Our jurisdiction-specific analyses were self-controlled and adjusted for calendar year to account for temporal trends; however, confounding remains possible. Although we found increased rates of fatal motor vehicle collisions and associated deaths following legalization, there was an amplification of the effect after we controlled for calendar year.

In contrast to other investigators, we did not select neighbouring or matched control jurisdictions as comparators; rather, we used the prelegalization period (minimum of $5 \mathrm{yr}$ ) for each jurisdiction to serve as the comparator for the period following legalization. Natural trends in the incidence of fatal motor vehicle collisions and associated deaths were roughly $\log$-linear before legalization in most jurisdictions. Although mild departures from linearity were present in some jurisdictions, to facilitate analyses across jurisdictions, we selected the modelling approach that was most appropriate for the most jurisdictions. Given the growing number of US jurisdictions with legalized cannabis, this approach minimizes the effect of spillover or contamination (i.e., residents of neighbouring states without legalization consuming cannabis purchased in states with legalized cannabis) on the analyses of association.

\section{Conclusion}

Our findings suggest that there is the potential for an important increase in fatal motor vehicle collisions following the legalization of recreational cannabis in Canada. Although differences between the US and Canada may mitigate potential increases in impaired driving, the observed $15 \%$ relative increase in fatal motor vehicle collisions and $16 \%$ relative increase in associated deaths could result in 308 additional road fatalities annually in Canada.

\section{References}

1. National Cannabis Survey 1st quarter, 2019. Ottawa: Statistics Canada; 2019. Available: https://www150.statcan.gc.ca/n1/daily-quotidien/190502/dq190502a -eng.htm (accessed 2019 May 31).

2. Cox C. The Canadian Cannabis Act legalizes and regulates recreational cannabis use in 2018. Health Policy 2018;122:205-9.

3. A framework for the legalization and regulation of cannabis in Canada: the final report of the Task Force on Cannabis Legalization and Regulation. Ottawa: Health Canada; 2016. Cat no H14-220/2016E-PDF. Available: http://healthycanadians.gc.ca/ task-force-marijuana-groupe-etude/framework-cadre/alt/framework-cadre-eng. pdf (accessed 2019 July 5).

4. Hartman RL, Huestis MA. Cannabis effects on driving skills. Clin Chem 2013; 59:478-92.

5. Lancione S, Wade K, Windle SB, et al. Non-medical cannabis in North America: an overview of regulatory approaches. Public Health 2020;178:7-14. 
6. Drug-impaired driving. Washington: Governors Highway Safety Association; 2019. Available: https://www.ghsa.org/state-laws/issues/drug\%20impaired $\% 20$ driving (accessed 2019 June 20).

7. Get the facts about marijuana. Anchorage (AK): Office of Substance Misuse and Addiction Prevention, Division of Public Health, Alaska Department of Health and Social Services; 2019. Available: http://dhss.alaska.gov/dph/ Director/Pages/marijuana/facts.aspx (accessed 2020 June 17).

8. Marijuana use and public health in Alaska - 2020. Anchorage (AK): Office of Substance Misuse and Addiction Prevention, Division of Public Health, Alaska Department of Health and Social Services; 2020. Available: http://dhss.alaska. gov/dph/Director/Documents/marijuana/MarijuanaUse_PublicHealth_Alaska 2020.pdf (accessed 2020 June 17).

9. Proposition 64: Adult Use of Marijuana Act. San Francisco: Judicial Council of California; 2016. Available: https://www.courts.ca.gov/documents/prop64 -Memo-20161110.pdf (accessed 2020 June 18).

10. First day of legal commercial cannabis activity. Sacramento (CA): Bureau of Cannabis Control; 2018. Available: https://cannabis.ca.gov/2018/01/01/more -than-400-state-licensed-cannabis-businesses-operating-on-californias-first-day -of-legal-commercial-cannabis-activity/ (accessed 2020 June 18).

11. Permanent rules related to the Colorado retail marijuana code. Denver: Colorado Department of Revenue, Marijuana Enforcement Division; 2013. Available: https://www.colorado.gov/pacific/sites/default/files/Retail\%20 Marijuana\%20Rules, \%20Adopted\%20090913,\%20Effective\%20101513\%5B1 \%5D_0.pdf (accessed 2020 June 20).

12. Marijuana legalization in Colorado: early findings. Denver: Colorado Department of Public Safety, Division of Criminal Justice, Office of Research and Statistics; 2016. Available: https://cdpsdocs.state.co.us/ors/docs/reports/ 2016-SB13-283-Rpt.pdf (accessed 2020 June 18).

13. The facts on DC marijuana laws. Washington: Metropolitan Police Department; 2020. Available: https://mpdc.dc.gov/marijuana (accessed 2020 June 18).

14. Recreational marijuana in Maine. Augusta (ME): Maine Legislature; 2020. Available: https://legislature.maine.gov/lawlibrary/recreational_marijuana_in_ maine/9419 (accessed 2021 Jan. 8).

15. Jones C. Maine and marijuana: sales of pot for recreational use start. USA Today (Tysons, VA). 2020 Oct. 9. Available: https://www.usatoday.com/story/ money/2020/10/09/maine-and-marijuana-sales-pot-legal-friday/5936647002/ (accessed 2021 Jan. 8).

16. Frequently asked questions (FAQs) regarding laws governing adult use marijuana in Massachusetts. Worchester (MA): Commonwealth of Massachusetts, Cannabis Control Commission; 2020. Available: http://cannabismass.wpengine. com/wp-content/uploads/2017/02/111717-FAQ-FINAL.pdf (accessed 2020 June 18).

17. Silva D, Kaplan E. Massachusetts makes history as first legal marijuana shops on East Coast open Tuesday. NBC News 2018 Nov. 19. Available: https://www. nbcnews.com/news/us-news/massachusetts-make-history-first-legal-marijuana -shops-east-coast-set-n938136 (accessed 2020 June 18).

18. Michigan Regulation and Taxation of Marijuana Act. Lansing (MI): State of Michigan, Michigan Legislature; 2018. Available: https://www.legislature. mi.gov/(S(0kujzj41 pcz3hdfvjbwzvmwv))/mileg.aspx? page=getObject\&objectNa me=mcl-Initiated-Law-1-of-2018 (accessed 2020 June 18).

19. Marijuana Regulatory Agency. Adult-use marijuana transfer window opens Sunday in Michigan [press release]. Lansing (MI): State of Michigan, Department of Licensing and Regulatory Affairs; 2019 Nov. 27. Available: https:// www.michigan.gov/lara/0,4601,7-154-11472-513379--,00.html (accessed 2020 June 18).

20. Did you have to be fully licensed under the Medical Marijuana Facilities Licensing Act (MMFLA) before November 1, 2019 to be eligible to receive an adultuse license? Lansing (MI): State of Michigan, Marijuana Regulatory Agency; 2020. Available: https://www.michigan.gov/mra/0,9306,7-386-83746-516597,00.html (accessed 2020 June 18).

21. Nevada marijuana law takes effect Jan. 1: know the legal do's and don'ts [press release]. Carson City (NV): State of Nevada, Department of Taxation; 2016. Available: https://tax.nv.gov/uploadedFiles/taxnvgov/Content/TaxLibrary/ Marijuana-Legal-Dos-and-Donts.pdf (accessed 2020 June 18).

22. Adult-use marijuana sales begin July 1 and Nevada officials want you to know how to stay legal and safe. Carson City (NV): State of Nevada, Department of Taxation; 2017. Available: https://tax.nv.gov/uploadedFiles/taxnvgov/Content/ TaxLibrary/Adult-Use\%20Marijuana\%20Sales\%20and\%20Licensed\%20Stores. pdf (accessed 2020 June 18).

23. Oregon's recreational cannabis laws go into effect [press release]. Portland (OR): State of Oregon, Oregon Liquor Control Commission; 2015 June 30. Available: https://www.oregon.gov/olcc/docs/news/news_releases/2015/nr_06_ 30 15 Effective date media release6-30.pdf (accessed 2020 June 18).

24. Early recreational marijuana sales to begin under Oregon Health Authority [press release]. Portland (OR): State of Oregon, Oregon Liquor Control Commission; 2015. Available: https://www.oregon.gov/olcc/docs/news/news_ releases/2015/nr_09_30_15_Early_Start_Marijuana.pdf (accessed 2020 June 18).

25. OLCC licensed marijuana retailers set to open October 1st: additional testing labs come online [press release]. Portland (OR): State of Oregon, Oregon Liquor Control Commission; 2016. Available: https://www.oregon.gov/olcc/ docs/news/news_releases/2016/nr_093016_FirstRetailLicenses.pdf (accessed 2020 June 18).
26. Q \& A for S.22 as passed by the Senate and House. Montpellier (VT): State of Vermont, Office of Legislative Council; 2018. Available: https:// marijuanacommission.vermont.gov/sites/mc/files/doc_library/Q\%20\%26\%20 A\%20for\%20S.\%2022.pdf (accessed 2020 June 18).

27. WSU outlines parameters for Initiative 502 marijuana law. WSU Insider [Pullman (WA): Washington State University] 2012 Dec. 5. Available: https://news. wsu.edu/2012/12/05/wsu-outlines-parameters-for-initiative-502-marijuana-law/ (accessed 2020 June 18)

28. FAQs on marijuana. Olympia (WA): Washington State Liquor and Cannabis Board; 2020. Available: https://lcb.wa.gov/mj2015/faqs_i-502 (accessed 2020 June 18).

29. Legal recreational marijuana States and DC. Santa Monica (CA): ProCon.org; 2019 [updated Feb. 2, 2021]. Available: https://marijuana.procon.org/view. resource.php? resourceID=006868 (accessed 2019 June 20).

30. National Highway Traffic Safety Administration. Fatality Analysis Reporting System (FARS) encyclopedia. Washington: United States Department of Transportation; 2019. Available: https://www-fars.nhtsa.dot.gov/Main/index. aspx (accessed 2019 July 4).

31. National Highway Traffic Safety Administration. Report to Congress NHTSA's Crash Data Collection Programs (DOT HS 811 337). Washington: United States Department of Transportation; 2010. Available: https:// crashstats.nhtsa.dot.gov/Api/Public/ViewPublication/811337 (accessed 2020 Aug. 3).

32. National Center for Statistics and Analysis. 2018 FARS/CRSS coding and validation manual (report no. DOT HS 812 828). Washington: United States Department of Transportation, National Highway Traffic Safety Administration; 2019. Available: https://crashstats.nhtsa.dot.gov/Api/Public/ViewPublication/812828 (accessed 2020 Aug. 3).

33. Chung C, Salottolo K, Tanner A 2nd, et al. The impact of recreational marijuana commercialization on traumatic injury. Inj Epidemiol 2019;6:3.

34. Sevigny EL. The effects of medical marijuana laws on cannabis-involved driving. Accid Anal Prev 2018;118:57-65.

35. Tefft BC, Arnold LS, Grabowski JG. Prevalence of marijuana involvement in fatal crashes: Washington, 2010-2014. Washington: AAA Foundation for Traffic Safety; 2016. Available: https://aaafoundation.org/wp-content/uploads/2017/12/ PrevalenceOfMarijuanaInvolvement.pdf (accessed 2019 July 5).

36. Hansen B, Miller K, Weber C. Early evidence on recreational marijuana legalization and traffic fatalities. Econ Inq 2020;58:547-68.

37. Fink DS, Stohl M, Sarvet AL, et al. Medical marijuana laws and driving under the influence of marijuana and alcohol. Addiction 2020;115:1944-53.

38. Aydelotte JD, Mardock AL, Mancheski CA, et al. Fatal crashes in the 5 years after recreational marijuana legalization in Colorado and Washington. Accid Anal Prev 2019;132:105284.

39. Santaella-Tenorio J, Wheeler-Martin K, DiMaggio CJ, et al. Association of recreational cannabis laws in Colorado and Washington State with changes in traffic fatalities, 2005-2017. FAMA Intern Med 2020;180:1061-8.

40. Kamer RS, Warshafsky S, Kamer GC. Change in traffic fatality rates in the first 4 states to legalize recreational marijuana. FAMA Intern Med 2020;180: 1119-20.

41. Lane TJ, Hall W. Traffic fatalities within US states that have legalized recreational cannabis sales and their neighbours. Addiction 2019;114:847-56.

42. Canadian motor vehicle traffic collision statistics: 2018. Ottawa: Government of Canada; 2019. Available: https://tc.canada.ca/en/canadian-motor-vehicle -traffic-collision-statistics-2018 (accessed 2019 July 5).

43. An Act to amend the Criminal Code (offences relating to conveyances) and to make consequential amendments to other Acts (S.C. 2018, c. 21). Available: www.parl.ca/ DocumentViewer/en/42-1/bill/C-46/royal-assent (accessed 2019 Feb. 26).

44. Canadian Society of Forensic Sciences Drugs and Driving Committee. Report on drug per se limits. 2017. Available: https://www.csfs.ca/wp-content/uploads/ 2017/09/Report-on-Drug-Per-Se-Limit.pdf (accessed 2019 June 20).

45. Roth A. The uneasy case for marijuana as chemical impairment under a science-based jurisprudence of dangerousness. California Law Review 2015;103: 841-918.

46. Tippetts AS, Voas RB, Fell JC, et al. A meta-analysis of .08 BAC laws in 19 jurisdictions in the United States. Accid Anal Prev 2005;37:149-61.

47. Villaveces A, Cummings P, Koepsell TD, et al. Association of alcohol-related laws with deaths due to motor vehicle and motorcycle crashes in the United States, 1980-1997. Am 7 Epidemiol 2003;157:131-40.

Affiliations: Lady Davis Institute (Windle, Eisenberg, Reynier, Cabaussel, Thombs, Grad, Ells, Sequeira, Filion) and Division of Cardiology (Eisenberg), Jewish General Hospital; Departments of Epidemiology, Biostatistics and Occupational Health (Windle, Eisenberg, Thombs, Filion), Medicine (Eisenberg, Thombs, Filion), Psychiatry (Thombs), Psychology (Thombs), Educational and Counselling Psychology (Thombs), Family Medicine (Grad, Ells) and Social Studies of Medicine (Ells), McGill University; Biomedical Ethics Unit (Ells), Division of Experimental Medicine, McGill University, Montréal, Que.

Contributors: Kristian Filion and Mark Eisenberg conceived of the study and supervised it. Pauline Reynier and Josselin Cabaussel analyzed the 
data. Sarah Windle drafted the manuscript. All of the authors contributed to the study design and data interpretation, approved the final version to be published and agreed to be accountable for all aspects of the work.

Funding: This study was funded by grant SHI-155407 from the Canadian Institutes of Health Research. Sarah Windle is supported by a Maysie MacSporran Graduate Studentship, an Alma Mater Fellowship and a Graduate Excellence Award from McGill University. Kristian Filion is supported by a Senior Research Scholar award from the Fonds de recherche du Québec - Santé (FRQS) and a William Dawson Scholar award from McGill University. Brett Thombs is supported by an FRQS research salary award.

Content licence: This is an Open Access article distributed in accordance with the terms of the Creative Commons Attribution (CC BY-NC-ND 4.0) licence, which permits use, distribution and reproduction in any medium, provided that the original publication is properly cited, the use is noncommercial (i.e., research or educational use), and no modifications or adaptations are made. See: https://creativecommons.org/licenses/ by-nc-nd/4.0/.

Data sharing: Data used in this study were accessed from the publicly available United States Fatality Analysis Reporting System database. These data are available at https://www-fars.nhtsa.dot.gov/Main/index. aspx.

Acknowledgement: The authors thank Hanan Abramovici $\mathrm{PhD}$ for his helpful suggestions.

Supplemental information: For reviewer comments and the original submission of this manuscript, please see www.cmajopen.ca/content/9/1/ E233/suppl/DC1. 